\title{
Budget projections and clinical impact of an immuno-oncology class of treatments: Experience in four EU markets
}

\author{
Boris Rachev $^{\mathrm{a}, *}$, Nils Wilking ${ }^{\mathrm{b}}$, Gisela Kobelt ${ }^{\mathrm{c}}$, Federico Spandonaro ${ }^{\mathrm{d}}$, Mirjana Rajer ${ }^{\mathrm{e}}$, \\ Alexander Roediger ${ }^{\mathrm{f}}$, Raphaël Normand ${ }^{\mathrm{f}}$, Christoph Zielinski ${ }^{\mathrm{g}}$ \\ ${ }^{a}$ Merck \& Co., Inc., 351 N Sumneytown Pike, North Wales, PA, 19454, USA \\ b Department of Oncology-Pathology, Karolinska Institutet, Solnavägen 1, 171 77, Solna, Sweden \\ ${ }^{\mathrm{c}}$ European Health Economics, 492 Chemin des Laurens, F-06530, Spéracèdes, France \\ ${ }^{\mathrm{d}}$ Universitá di Roma Tor Vergata, Via Cracovia, 50, 00133, Roma, RM, Italy \\ e Oncology Institute Ljubljana, Zaloška cesta 2, 1000, Ljubljana, Slovenia \\ ${ }^{\mathrm{f}}$ MSD International GmbH, Ringstrasse 27, 6010, Kriens, Switzerland \\ ${ }^{g}$ Vienna Cancer Center (VCC), Vienna Medical University, BT86/E 01, Spitalgasse 23, 1090, Wien, Austria
}

\section{A R T I C L E I N F O}

\section{Keywords:}

Immuno-oncology

PD-1/PD-L1

Budget projections

Clinical impact

\begin{abstract}
A B S T R A C T
Background: Immunotherapies have revolutionized oncology, but their rapid expansion may potentially put healthcare budgets under strain. We developed an approach to reduce demand uncertainty and inform decision makers and payers of the potential health outcomes and budget impact of the anti-PD-1/PD-L1 class of immunooncology (IO) treatments.

Methods: We used partitioned survival modelling and budget impact analysis to estimate overall survival, progression-free survival, life years gained (LYG), and number of adverse events (AEs), comparing "worlds with and without" anti-PD-1/PD-L1s over five years. The cancer types initially included melanoma, first and second line non-small cell lung cancer (NSCLC), bladder, head and neck, renal cell carcinoma, and triple negative breast cancer [1]. Inputs were based on publicly available data, literature, and expert advice.

Results: The model [2] estimated budget and health impact of the anti-PD-1/PD-L1s and projected that between 2018-2022 the class [3] would have a manageable economic impact per year, compared to the current standard of care (SOC).

The first country adaptations showed that for that period Belgium would save around 11,100 additional life years and avoid 6,100 AEs. Slovenia - 1,470 LYGs and 870 AEs avoided; Austria - respectively 4,200, 3,000; Italy $19,800,6,800$. For Austria, the class had a projected share of about $4.5 \%$ of the cancer care budget and $0.4 \%$ of the total 2020 healthcare budget. For Belgium, Slovenia, and Italy - respectively $15.1 \%$ and $1.1 \%, 12.6 \%, 0.6$ $\%$, and $6.5 \%, 0.5 \%$.

Conclusion: The Health Impact Projection (HIP) is a horizon scanning model designed to estimate the potential budget and health impact of the PD-(L)1 inhibitor class at a country level for the next five years. It provides valuable data to payers which they can use to support their reimbursement plans.

Policy Summary: The model is a strategic tool which allows decisionmakers to assess the implications of policy decisions, such as additional investment, or accelerated access to IOs. It can drive tangible population health benefits by eliminating the questions around PD-(L)1 inhibitor spending and its related outcomes.
\end{abstract}

\section{Introduction}

Cancer care remains one of the most discussed global health policy issues. The number of people affected by cancer is rising, and health systems are pressed to plan for the costs associated with investment in innovative drugs. According to the recently updated Comparator Report, published by the Swedish Institute for Health Economics, in the European Union "cancer medicines have accounted for a modest but growing share of total pharmaceutical expenditure" [4], reflecting increasing prices but also rapid development in cancer cures: in 1996, a physician

\footnotetext{
* Corresponding author at: Merck \& Co., Inc., 351N Sumneytown Pike, North Wales, PA, 19454, USA.

E-mail address: boris.rachev@merck.com (B. Rachev).
} 
had 4 treatment options in lung cancer, in 2016 she had 19 [5]. Ten years ago, only 5 out of 100 patients with skin cancer were alive 5 years after they were diagnosed - today, every second patient can expect to be alive [6]. Although in recent years significant advances in cancer diagnosis and treatment have resulted in declining cancer-related mortality rates, cancer is still the leading cause of death behind cardiovascular diseases: in 20165.2 million people died in Europe, 1.4 million of them from cancer - more than one in four deaths [4].

The growing array of treatment options and their potential use has led to concerns around the long-term affordability of IOs. For example, by 2025 , the global cancer drug market's worth is estimated at $\$ 176$ billion, up from $\$ 97$ billion in 2017. Targeted and immuno-therapies are expected to contribute to that rise, with PD-1/PD-L1 inhibitors expecting the highest rate of growth [7]. Such rapid growth requires clarity and transparency of the costs and benefits of the anti-PD-1/PD-L1 class [3]. The funding decisions of governments, payers, and health authorities to finance ground-breaking cancer therapies need greater predictability, and a better understanding of the associated improvements in patient outcomes.

The HIP model [2] was conceptualized in 2017 with the first country adaptations based on 2017 and 2018 data. The model estimates key clinical and economic outcomes of PD-1/PD-L1 inhibitors across indications compared to SOC treatments over a 5-year period at a county level. It is based on a set of assumptions (see Appendix C) and draws on budget impact analysis for its structure and methods, while also projecting related health benefits. Given the stakeholder target audience sick funds, healthcare ministries, budget planners, and patient organizations, we deemed appropriate to focus the model on obtaining a high-level estimate of the costs and benefits of the class.

\section{Data and methodology}

The inputs used in the HIP were sourced from available data on the products in the class (Fig. 1). When data were missing, comparable product figures were used instead.

Country-level (local) data define the context of the analysis, reflecting the characteristics of a country's population and market. Parameters such as size and growth of the population, proportion of patients who undergo PD-1/PD-L1 testing, and IO market share (See Appendix B), are also included.

For epidemiology data, the HIP model considers newly diagnosed patients with advanced stages of cancer (e.g., local advanced and metastatic).

The populations considered in the model are closely aligned with the subgroups approved within each indication in the respective clinical trials. No patients in these subgroups were assumed to be switching treatment. The model also restricted the eligible population based on PD-L1 testing. For example, included 1 L NSCLC patients would be those with the characteristics of the selected trial population in this indication, following the clinical trial protocol. ${ }^{1}$

Market share inputs describe the projected uptake of treatments over the 5-year period. The HIP model relied on publicly available financial analysis reports [8] showing projections for the US market and the 'rest of the world' and regulatory approval timelines for each of the indications [9]. The market shares were then approved or adjusted, based on country expert opinions, to align with each country's reimbursement system (see Appendix B).

The HIP model projections are based on publicly available list prices for anti-PD-1/PD-L1s, as informed by the respective national formularies, and clinical evidence, based on key clinical trials (Table 2). Hernandez et al. (2020) investigate that although net prices for branded

\footnotetext{
${ }^{1}$ E.g., oncogene non-addiction, patients eligible are tested with PD-L1 and have an IHC $>50 \%$, and measurement of health gains was limited within the relevant patient subset.
}

products in the US have been growing between 2007-2018, they seem to have levelled in 2014, and decreased in 2017-18, while list prices continued rising [10]. To a lesser extent outside US, this trend could still mean that the HIP budget impact calculations using 2017-18 list prices may have overestimated anti-PD-1/PD-L1 budget projections.

The adopted selection criterion for clinical trials in the base case model was the use of the most conservative trial data from the approved treatment options. Where trials failed to show significant benefits the assumption was that the reimbursement would not be successful within that indication for the suggested treatment, hence the outcomes observed in the failed trials would not be relevant to those patients that would be treated with an anti-PD-1/PD-L1 therapy.

The model (Fig. 2) also used survival gains and outcomes associated with a particular anti-PD-1/PD-L1 treatment as representative of the whole class in that indication. Whenever more than one clinical trial was available, we used the trial with the smallest difference in median PFS between the anti-PD-1/PD-L1 drug and the SOC [22]. This condition was later relaxed - if there was more than one clinical trial per indication, the user could select the trial whose data were considered to be the best representation of clinical practice in a given country.

The modelling methodology used to estimate the key survival outcomes in each world was partitioned survival modelling (See Appendix A). The survival curves relating to SOC and anti-PD-1/PD-L1s were modelled using different approaches. As the model considers a five-year horizon, where trial data were only observable for a shorter time, SOC survival curves were fitted and then extrapolated into the future, assuming the survival data follows an exponential distribution [23]. Partitioned survival and Markov modelling have been shown to produce 'functionally equivalent' results, if survival data from clinical trials have been modelled correctly [24].

The hazard ratios of the anti-PD-1/PD-L1 treatment versus SOC were estimated from the relevant clinical trials (Table 2), applied to the SOC survival curves and used to derive the survival curves for the corresponding anti-PD-1/PD-L1 treatment in each indication. Goodness of fit was visually inspected and when the modeled curves did not show an accurate representation of the entire survival curve from a trial, or a realistic extrapolation of the latter into the future, changes were made to improve the fit.

The survival curves for anti-PD-1/PD-L1 products were observed to taper off or plateau in several indications. In the indications where the anti-PD-1/PD-L1 survival curve appeared to taper off, it was broken into two parts, each associated with its own hazard ratio and corresponding shape.

Only direct costs were included in the model adaptation (see Appendix B), in line with budget impact modeling (BIM) guidelines recommending that indirect costs are not included unless they have consequences for the budget holder [25-27]. Nevertheless, the model still allows for the inclusion of indirect costs, where the decision was left with the countries. Total costs were estimated by adding the costs of individual products and obtaining a weighted average using the market share for each product.

The five-year time horizon in the model fits BIM guidelines as well [25-27]. Health economics experts were involved with the validation of the model assumptions and their advice and feedback on the study was largely incorporated.

The longest, rather than the median, duration of treatment was used in the HIP model as a cap on the absolute maximum length of patient treatment (around two years for the class, but varying number of weeks per indication).

\section{The increase of cancer incidence in Europe - the experience of Austria, Belgium, Slovenia, and Italy}

The HIP adaptations for Austria, Belgium, Slovenia, and Italy [28] used the model to inform planning of immunotherapy funding and maintain a constructive dialogue with payers and healthcare authorities 


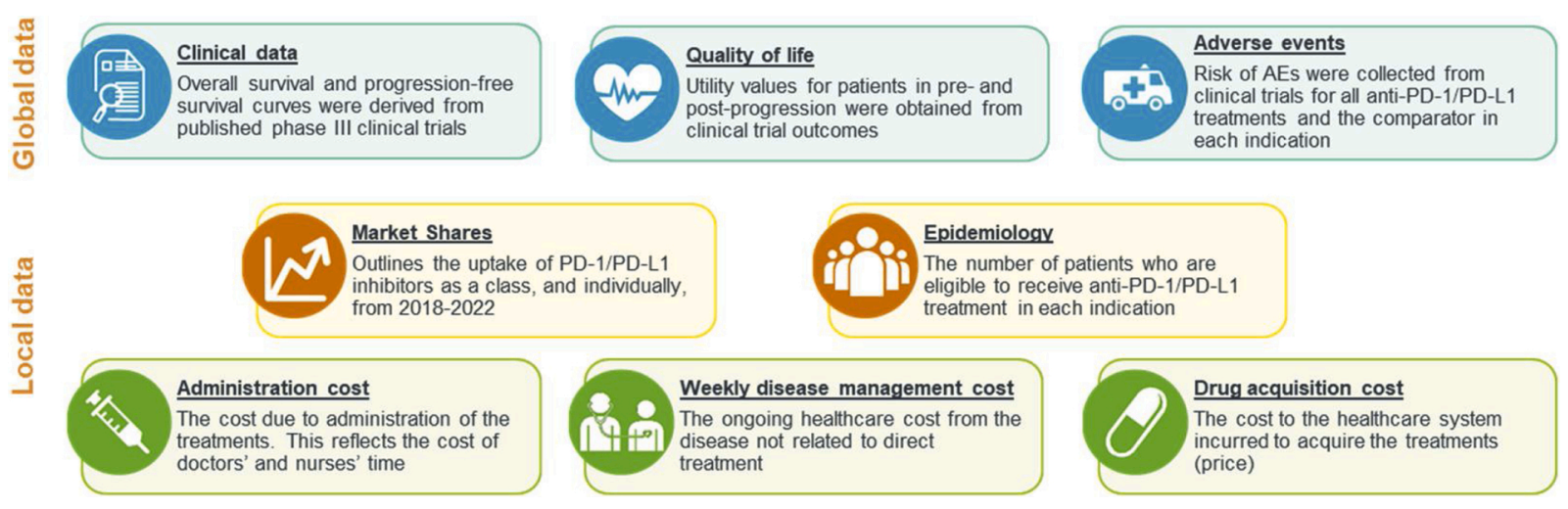

Fig. 1. Global and local data inputs.

Table 1

Indications and corresponding PD-1/PD-L1 treatments per country in the model (2018-22).

\begin{tabular}{|c|c|c|}
\hline Country & Indications & PD-1/PD-L1s \\
\hline \multirow{7}{*}{ Italy } & Unresectable or metastatic & Pembrolizumab, Nivolumab, \\
\hline & Metastatic first-line non- & $\begin{array}{l}\text { Atezolizumad } \\
\text { Pembrolizumab Nivolumab }\end{array}$ \\
\hline & small cell lung cancer $(1 \mathrm{~L}$ & Atezolizumab, Durvalumab, \\
\hline & NSCLC) & Avelumab \\
\hline & $\begin{array}{l}\text { Metastatic triple negative } \\
\text { breast cancer (TNBC) }\end{array}$ & Pembrolizumab, Atezolizumab \\
\hline & $\begin{array}{l}\text { Recurrent or metastatic } \\
\text { head and neck cancer }\end{array}$ & $\begin{array}{l}\text { Pembrolizumab, Nivolumab, } \\
\text { Durvalumab }\end{array}$ \\
\hline & $\begin{array}{l}\text { Locally advanced or } \\
\text { metastatic bladder cancer }\end{array}$ & $\begin{array}{l}\text { Pembrolizumab, Nivolumab, } \\
\text { Atezolizumab, Durvalumab, } \\
\text { Avelumab }\end{array}$ \\
\hline \multirow{7}{*}{$\begin{array}{l}\text { Slovenia, } \\
\text { Belgium, } \\
\text { Austria }\end{array}$} & $\begin{array}{l}\text { Unresectable or metastatic } \\
\text { melanoma (melanoma) }\end{array}$ & $\begin{array}{l}\text { Atezolizumab, Pembrolizumab, } \\
\text { Nivolumab }\end{array}$ \\
\hline & $\begin{array}{l}\text { Metastatic first-line non- } \\
\text { small cell lung cancer ( } 1 \mathrm{~L} \\
\text { NSCLC) }\end{array}$ & $\begin{array}{l}\text { Pembrolizumab, Nivolumab, } \\
\text { Atezolizumab, Durvalumab, } \\
\text { Avelumab }\end{array}$ \\
\hline & $\begin{array}{l}\text { Locally advanced or } \\
\text { metastatic } 2 \text { L NSCLC }\end{array}$ & $\begin{array}{l}\text { Pembrolizumab, Nivolumab, } \\
\text { Atezolizumab, Durvalumab, } \\
\text { Avelumab }\end{array}$ \\
\hline & $\begin{array}{l}\text { Metastatic triple negative } \\
\text { breast cancer (TNBC) }\end{array}$ & Atezolizumab, Pembrolizumab \\
\hline & $\begin{array}{l}\text { Recurrent or metastatic } \\
\text { head and neck cancer }\end{array}$ & $\begin{array}{l}\text { Durvalumab, Nivolumab, } \\
\text { Pembrolizumab (+Docetaxel in } \\
\text { Austria) }\end{array}$ \\
\hline & $\begin{array}{l}\text { Locally advanced or } \\
\text { metastatic bladder cancer }\end{array}$ & $\begin{array}{l}\text { Avelumab, Atezolizumab, } \\
\text { Durvalumab, Nivolumab, } \\
\text { Pembrolizumab }\end{array}$ \\
\hline & $\begin{array}{l}\text { Locally advanced or } \\
\text { metastatic renal cell } \\
\text { carcinoma }\end{array}$ & $\begin{array}{l}\text { Avelumab, Atezolizumab, } \\
\text { Nivolumab, (+ Pembrolizumab } \\
\text { for Slovenia) }\end{array}$ \\
\hline
\end{tabular}

Source: Cowen \& Company Equity Research "PD-1/PD-L1 Market Model Update", March 14, 2017. Data for products not expected to be on the market in this period are not presented. See also Reference [[1]] in the "References" section for Italy's indications vs the rest.

\section{about IO spending.}

The project faced an increasing cancer disease burden - incidence increased by around 50 percent from 2.6 million to 3.9 million cases between 1995 and 2018 [4]. The main factors for this increase were population growth and population aging. Over the same period, however, fewer people have died of cancer as a result of advances in screening, diagnosis, and treatment, including PD-1/PD-L1 inhibitors [29].

The cancer care direct costs for the same period (1995-2018) increased by 89 percent from $€ 52$ billion to $€ 99$ billion (2018 prices), although spending on cancer as a share of total health expenditure has been relatively stable over time [4].

On this background, the first adopters of the HIP - Austria, Belgium,
Slovenia, and Italy have, overall, followed the common European trends.

According to the Belgian Cancer Registry, there were 67,087 new diagnoses of cancer in 2015. Due to ageing population, the incidence of cancer in Belgium was expected to increase by $17 \%-79,140$ by 2025 [30]. This number, however, was surpassed in 2020 with the Belgian Cancer Registry reporting 83,267 new cases [31]. As part of the HIP, Belgium created two access scenarios - within a month and one year after EMA approval, highlighting the impact of accelerated access on health outcomes.

In Slovenia, new cases of cancer in 2015 reached 14,329. Within 20 years (1995-2015), the annual cancer incidence rate has increased by $0.6 \%$, resulting in an increase in the healthcare spend on cancer [32]. The World Health Organization indicated that cancer control will be one of the next major challenges for the Slovenian healthcare system due to the high concentration of cancer in older populations, as well as increased life expectancy [33]. According to the Slovenian Institute of Macroeconomic Analysis and Development, the country's population is ageing more quickly than in other EU countries [34], indicating a need for more investment in innovative cancer therapies.

While cancer epidemiology in Italy has followed the common European trend, incidence has been higher $(9.9 \%)$ compared to the EU average [35]. In 2019 there were about $3.5 \mathrm{mln}$ people living in Italy with a cancer diagnosis. Lung cancer represents still the most frequent cause of death, followed by colon cancer, breast, pancreas, and liver. Data collected by the network of Italian Cancer Registries (AIRTUM) which provides incidence, survival, and prevalence numbers for about 200 different cancer entities, projected that about 371,000 new cancer diagnoses were expected by the end of 2019 [36].

The cancer incidence in Austria (except non-melanoma skin cancer) has been lower than the EU incidence rate - 355.5 per 100,000 - around 23 per 100,000 lower than the EU average [37]. Decentralized planning and delegation of responsibilities reportedly lead to fragmentation and inadequate coordination - further investments in oncology are a recurring subject of discussion, as malignant neoplasms are currently the second largest cause of deaths in the country [4].

The results below show projected health outcomes data from HIP for these countries as a group, without making any country comparisons, but rather showing common trends despite country differences. For example, the targeted indications varied from country to country, e.g., Italy did not include $2 \mathrm{~L}$ NSCLC and TNBC in the model adaptation [1].

The projections in Fig. 3 and Table 3 show the impact of PD-1/PD-L1 inhibitors on life years gained based on the expected number of patients eligible for treatment and indication mortality. The 2 L NSCLC estimates assume that those who progress after the first year of $1 \mathrm{~L}$ NSCLC SOC treatment are eligible to receive anti-PD-1/PD-L1 agent in $2 \mathrm{~L}$ NSCLC in the following year, that patients on anti-PD-1/PD-L1s cannot be treated with another PD-1/PD-L1 in $2 \mathrm{~L}$, and that most patients progress one year after initiating $1 \mathrm{~L}$ treatment. This applies to all patient cohorts 
Table 2

Overview of the SOC and trials used in Austria, Belgium, Italy, and Slovenia [11-21].

\begin{tabular}{|c|c|c|c|}
\hline Indication & Country & $\begin{array}{l}\text { SOC used in the modelled } \\
\text { countries (Local input) }\end{array}$ & $\begin{array}{l}\text { Trial used for } \\
\text { survival analysis } \\
\text { (Global input) }^{\mathrm{a}}\end{array}$ \\
\hline Melanoma & $\begin{array}{l}\text { Italy } \\
\text { Austria, } \\
\text { Belgium, } \\
\text { Slovenia }\end{array}$ & $\begin{array}{l}\text { Dabrafenib + trametinib } \\
\text { Ipilimumab }\end{array}$ & KEYNOTE 006 \\
\hline $1 \mathrm{JSCIC}^{\mathrm{b}}$ & Italy & Pemetrexed + cisplatin & $\begin{array}{l}\text { KEYNOTE } 407 \\
\text { and KEYNOTE } \\
189\end{array}$ \\
\hline & $\begin{array}{l}\text { Austria, } \\
\text { Belgium, } \\
\text { Slovenia }\end{array}$ & Chemotherapy & KEYNOTE 024 \\
\hline 2 L NSCLC & $\begin{array}{l}\text { Austria, } \\
\text { Belgium, } \\
\text { Slovenia }\end{array}$ & Docetaxel & CheckMate 017 \\
\hline TNBC & $\begin{array}{l}\text { Slovenia, } \\
\text { Austria } \\
\text { Belgium }\end{array}$ & $\begin{array}{l}\text { Platinum-based } \\
\text { chemotherapy } \\
\text { Gemcitabine }\end{array}$ & $\begin{array}{l}\text { Zhang et al. } \\
2015^{\dagger}\end{array}$ \\
\hline Head and & $\begin{array}{l}\text { Italy } \\
\text { Austria }\end{array}$ & $\begin{array}{l}\text { Chemo platinum }+5 \text { - } \\
\text { FU } \pm \text { cetuximab } \\
\text { Systemic therapy }\end{array}$ & KEYNOTE 048 \\
\hline & $\begin{array}{l}\text { Slovenia } \\
\text { Belgium } \\
\text { Italy }\end{array}$ & $\begin{array}{l}\text { Cetuximab } \\
\text { Chemotherapy } \\
\text { Vinflunine }\end{array}$ & Checkmate 141 \\
\hline Bladder & $\begin{array}{l}\text { Slovenia, } \\
\text { Austria } \\
\text { Belgium }\end{array}$ & $\begin{array}{l}\text { Chemotherapy } \\
\text { Paclitaxel }\end{array}$ & KEYNOTE 045 \\
\hline Renal & $\begin{array}{l}\text { Italy } \\
\text { Slovenia, } \\
\text { Austria, } \\
\text { Belgium }\end{array}$ & Sunitinib & Checkmate 025 \\
\hline
\end{tabular}

NSCLC: Non-small cell lung cancer; SOC: Standard of care, TNBC: Triplenegative breast cancer.

$\dagger$ Zhang et al. (2015) was used to obtain progression-free survival (PFS) and overall survival (OS) Kaplan-Meier curves for extrapolation, prior to the publication of KEYNOTE and IMPassion trials in TNBC.

$t^{\dagger}$ In the CHECKMATE 141 trial patients with recurrent or metastatic head and neck carcinoma were treated with investigators choice of Cetuximab, Methotrexate or Docetaxel as the standard of care. In the KEYNOTE 045 trial, patients with recurrent or metastatic urothelial cancer were treated with investigators' choice of paclitaxel, vinflunine or docetaxel as the standard of care. Data for docetaxel were used for the posology of the regimen.

${ }^{¥}$ In the KEYNOTE 045 trial, patients with recurrent or metastatic urothelial cancer were treated with investigator's choice of paclitaxel, vinflunine or docetaxel as the standard of care. Data for docetaxel were used for the posology of the regimen.

a See also Table 1 for a full list of modelled treatments per indication.

b The impact of 1 L NSCLC treatment on 2 L NSCLC treatment was incorporated through the selection of the $2 \mathrm{~L}$ input values. To achieve this, the eligible population size and uptake rates for the $2 \mathrm{~L}$ patient population were selected to reflect the expected utilization of anti-PD-1/PD-L1 products within the $1 \mathrm{~L}$ setting, e.g., in 2 L NSCLC, the use of anti PD-1/PD-L1 therapies was expected to decrease as a direct consequence of the increase in the uptake of the class in $1 \mathrm{~L}$ NSCLC.

entering the model annually for the whole 5-year period. The projections of life years gained for Austria, Belgium, Italy, and Slovenia show that the treatment of $1 \mathrm{~L}$ and $2 \mathrm{~L}$ NSCLC had the greatest LYG impact: for Belgium - $75 \%$ of the total LYG, Austria - $72 \%$, Slovenia - 58 $\%$, and Italy $-80 \%$.

In the adaptations for the four countries, the data was collated prior to the launch of the combination therapies in 1 L NSCLC (e.g., KN 189 and $\mathrm{KN} 407$ ) and therefore only reflect monotherapy use (e.g., KN 024).

The anti-PD-1/PD-L1s come at a higher cost than the alternatives in cancer care but have allowed new patient groups to be treated. This trend is expected to bump up direct costs and is likely to continue in the foreseeable future (see Fig. 4, Table 4). The share of cancer medicine budget that PD-1/PD-L1 inhibitors require will be mainly dependent on budget priorities, uptake, as well as approved indications. While for Austria ( $€ 108$ cancer spend per capita) and Belgium ( $€ 90$ per capita) the projected budget growth is expected to slightly decline after 2020-21, for Italy (€75 per capita) and Slovenia ( $€ 51$ per capita) [36] it will continue growing into 2022 .

\section{Discussion}

Using the HIP adaptations in Austria, Belgium, Italy, and Slovenia, the study shows that anti-PD-1/PD-L1 treatments are expected to provide improvements in health outcomes, with health gains gradually increasing between 2018-2022. Direct costs will continue to rise in parallel with the uptake increase of PD-1/PD-L1 inhibitors. First line NSCLC is the largest contributor to the class budget impact - it leads the other indications in health gains, and costs, due to the size of the affected population.

For all four countries the projections show that the additional expenditure on anti-PD-1/PD-L1 medicines in 2018 would be less than $7 \%$ of the total cancer care spend and less than half of a percent of the countries' total healthcare budget. These projections, however, are expected to double percentage wise in 2020 (with the exception of Austria). Several factors could be at play - according to the Comparator Report, cancer "has surpassed cardiovascular diseases and become the disease group causing the greatest burden...in mostly wealthier countries" [4], as well as the expected increase in anti-PD-1/PD-L1 uptake, population ageing and longevity, increased incidence, and the substitution effect with SOC treatments as anti-PD-1/PD-L1s become the standard of care themselves.

The HIP model enables policymakers to acquire a perspective on the impact of anti-PD-1/PD-L1s on health gains and budgets, exploring the implications of different policy decisions, such as updating oncology budgets with additional funds for immunotherapy.

Since immuno-oncology has seen rapid development, the model allows new data to be added when it becomes available for a continuous model update and to correct for changes in the market, such as the introduction of new combination therapies.

\section{Key limitations}

The HIP model was developed as a deterministic model, producing only point estimates, which can lead to uncertainty around many of the included parameter values. It is a horizon scanning tool with highly variable assumptions, across a spectrum of diverse cancer indications, and its base case did not include sensitivity analysis. The treatment landscape has changed since 2017 and a broader use of immunotherapy now and in the future may affect the projections and raise further questions. For example, the literature shows that to determine the optimum dose for monoclonal antibodies treatment is a challenge and speculates that the utilization of a flat-dose treatment could be a contributor to an increase in total costs [38].

The validity of the HIP model relies on a set of assumptions, which are central to ensuring the consistency of the study results (Appendix C). Several of them were made due to lack of data, which may underestimate the true impact of the therapies. One key limitation, for example, is the reliance on a single SOC and anti-PD-1/PD-L1 survival estimate to model the comparison between the SOC and the anti-PD-1/PD-L1 class in each country. Such comparison was used due to the complexity of the alternatives at that time.

Health outcomes are likely to be underestimated due to the relatively short time-horizon employed in the HIP model. For example, patients who start treatment in 2022 will accrue most of their costs of treatment, however, most of the health gains from anti-PD-1/PD-L1 treatment are not going to be realized until later stages as most benefits are only achieved beyond the time-horizon of this model.

The method used to model survival in the HIP model relies on visual inspection as the key criterion used to select the hazard ratios and the 


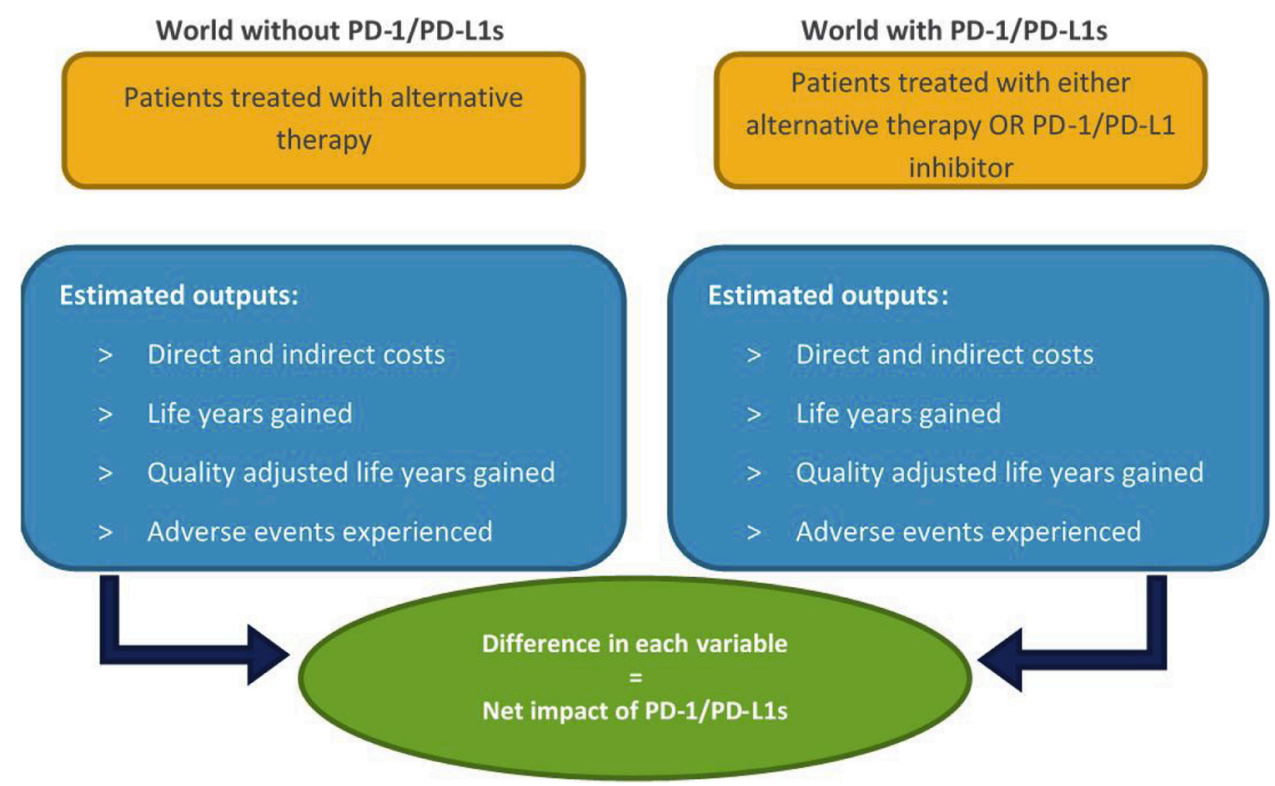

Fig. 2. Diagram of the model structure.
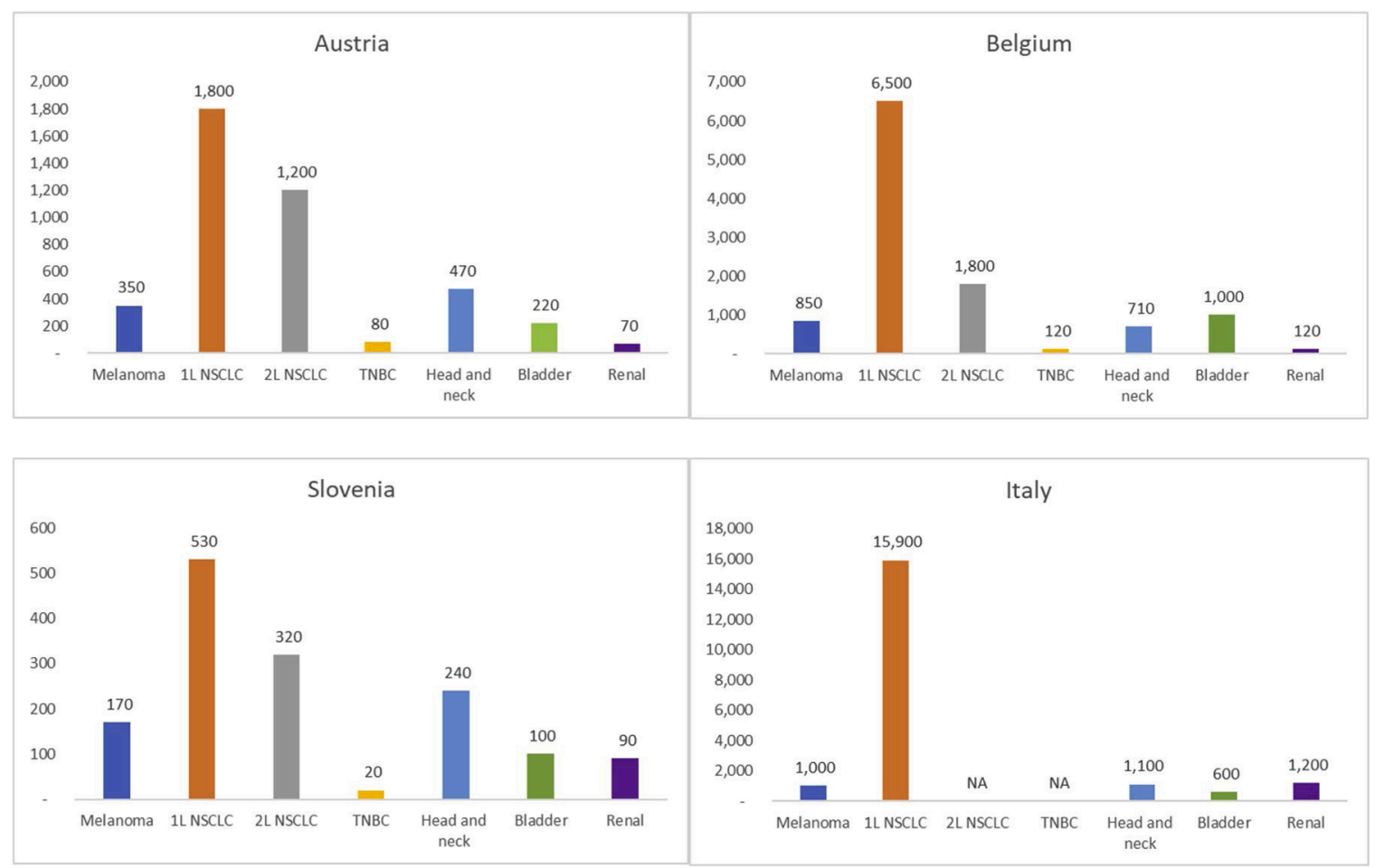

Fig. 3. Projected life years gained over a 5-year time horizon by country.

Note: Scale is different for different countries to capture trends, rather than differences. Austria and Slovenia assumed $100 \%$ treatment rate for all eligible patients to project a "fully loaded" budget impact, while Belgium and Italy assumed more "realistic" ones - $80 \%$ and $50 \%$, respectively. "N/A" in the case of Italy means that indications were not included in the adaptation, as clarified in Reference [1].

time period cut-off point along each survival curve. Such qualitative method is simple and intuitive but lacks the rigor of the more advanced statistical techniques as the extrapolated estimates are based on the shape of the curves.

A related limitation is that the interpretation of "plateau" could be somewhat subjective. The possibility of overestimating the plateau effect based on the "shape" of the curves, while not considering the number of events for which those plateaus persist, could possibly lead to debatable interpretations. Nonetheless, the updated analysis of Keynote-
024 confirmed the "plateau" effect for 1 L NSCLC in a subsequent longterm follow up study [39].

The lack of anti-PD-1/PD-L1 market share data in the four countries, and the reliance on proxy assumptions provided by global market reports (e.g., the Cowen Report [9]) could have potentially biased the budget projections in either direction. The uptake of anti-PD-1/PD-L1s was also expected to remain either constant or increase over the five modelled years, barring the impact of events such as the current COVID-19 pandemic. 
Table 3

Total projected health gains by patient population in Austria, Belgium, Italy, and Slovenia (2018-2022).

\begin{tabular}{lllll}
\hline \multicolumn{4}{l}{ PD-1/PD-L1 } & Inhibitor vs SOC \\
\hline Country & Belgium & Slovenia & Austria & Italy \\
Life years gained & 11,100 & 1,470 & 4,200 & 19,800 \\
Quality adjusted life years gained & 9,600 & 1,100 & 3,500 & 13,800 \\
Progression free life years gained $^{\text {High-grade AEs avoided }}{ }^{\mathrm{a}}$ & 13,600 & 1,400 & 3,800 & 14,100 \\
High $^{2}$ & 6,100 & 870 & 3,000 & 6,800 \\
\hline
\end{tabular}

${ }^{a}$ Quality of life data was used in the form of utility measures, taken for patients in each health state for each of the treatment options. The high-grade adverse events were part of an additional analysis within the framework and therefore did not impact on the QoL assessment as the impact of adverse reactions was already captured within the sourced utility measures.

\section{Summary}

The model offers a flexible tool to project the budget and health impact of anti-PD-1/PD-L1s over five years and help decisionmakers acquire the insight needed to support their budget plans. The HIP model results for Austria, Belgium, Italy and Slovenia show that the introduction of the PD-1/PD-L1 inhibitor class in 2017 could lead to more than 36,570 life years gained and 16,770 high-grade AEs avoided, just in the following five years.

The horizon scanning approach has the potential to facilitate a more targeted discussion about investment in immune-oncology treatments and innovative healthcare technologies in general.

\section{Funding}

Funding for this research was provided by Merck Sharp \& Dohme Corp., a subsidiary of Merck \& Co., Inc., Kenilworth, NJ, USA.

\section{Transparency document}

The Transparency document associated with this article can be found in the online version.

\section{Declaration of Competing Interest}

Boris Rachev, Alexander Roediger, and Raphaël Normand are employees of Merck Sharp \& Dohme Corp. or MSD, a subsidiary of Merck \& Co., Inc., Kenilworth, NJ USA, who may own stock and/or hold stock options in the Company.

Frederico Spandonaro, professor at Universitá di Roma Tor Vergata, Italy, and Nils Wilking, professor at Department of Oncology-Pathology, Karolinska Institutet, Stockholm and Dr. Gisela Kobelt, of European Health Economics were hired by Merck \& Co., Inc., Kenilworth, NJ USA, to provide methodological support for the HIP project.

Christoph Zielinski, an employee at Vienna Cancer Center (VCC),
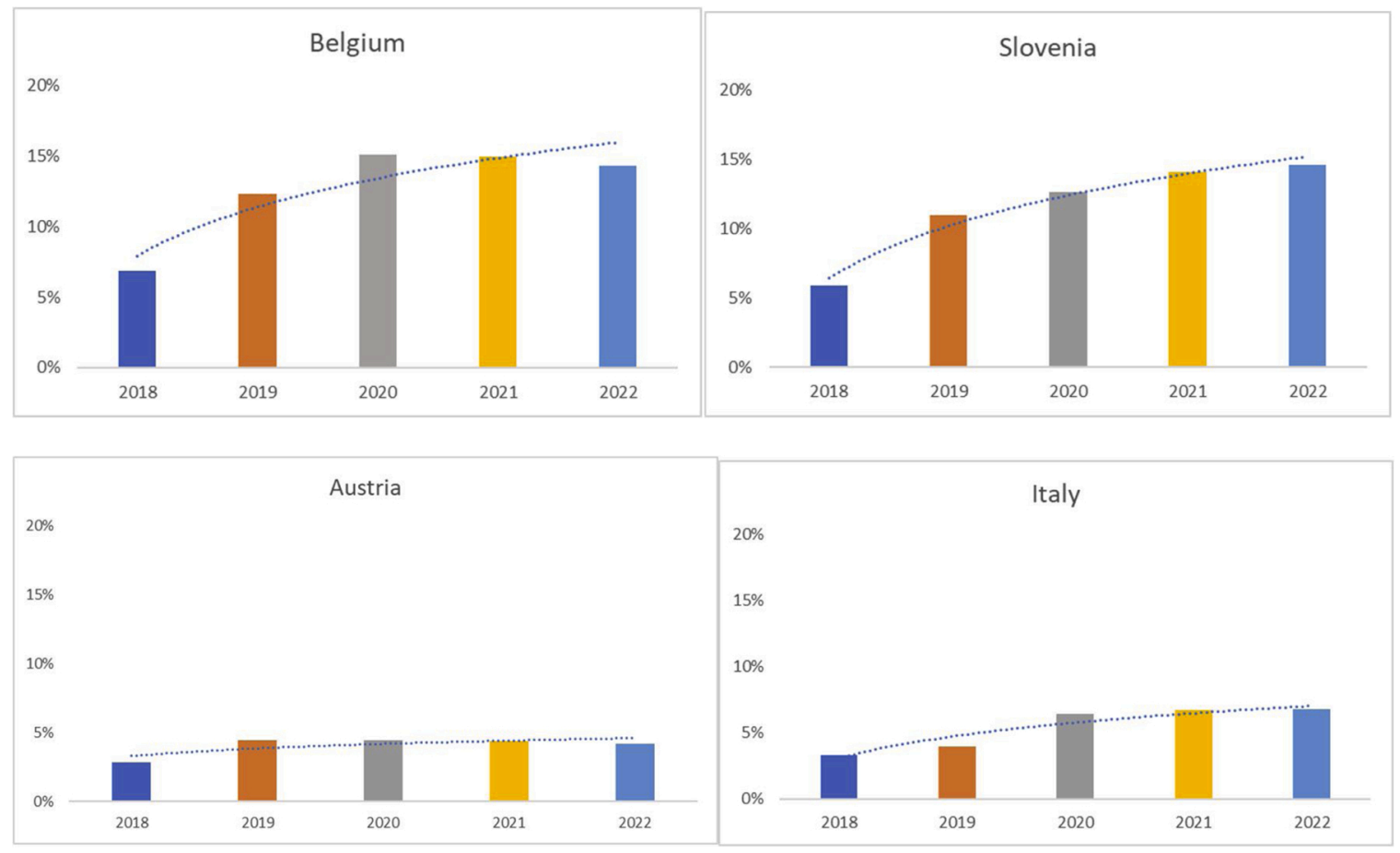

Fig. 4. Projected PD-1/PD-L1 budget impact as a percentage of total cancer expenditures (2018-2022).

Table 4

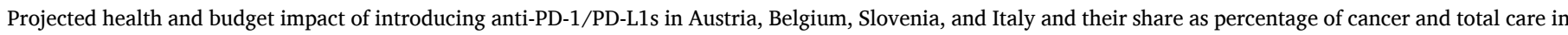
2018 and 2020.

\begin{tabular}{|c|c|c|c|c|c|c|}
\hline Country & $\begin{array}{l}\text { LYG, average } \\
(2018-2022)\end{array}$ & $\begin{array}{l}\text { AEs avoided, average } \\
(2018-2022)\end{array}$ & $\begin{array}{l}\% \text { of the total cancer care } \\
\text { expenditure in } 2018\end{array}$ & $\begin{array}{l}\% \text { of the total healthcare } \\
\text { expenditure in } 2018\end{array}$ & $\begin{array}{l}\% \text { of the total cancer care } \\
\text { expenditure in } 2020\end{array}$ & $\begin{array}{l}\% \text { of the total healthcare } \\
\text { expenditure in } 2020\end{array}$ \\
\hline Austria & 4,200 & 3,000 & 3.0 & 0.2 & 4.5 & 0.4 \\
\hline Belgium & 11,100 & 6,100 & 7.0 & 0.5 & 15.1 & 1.1 \\
\hline Slovenia & 1,470 & 870 & 6.0 & 0.5 & 12.6 & 0.6 \\
\hline Italy & 19,800 & 6,800 & 3.3 & 0.2 & 6.5 & 0.5 \\
\hline
\end{tabular}

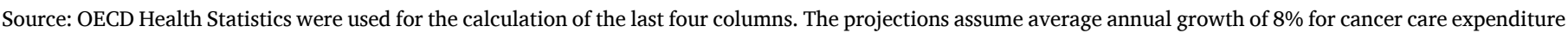
and $3 \%$ for total healthcare expenditure. 
Vienna Medical University, owns stock in MSD.

\section{Acknowledgement}

The authors are grateful to Julie van Bavel, James Pellissier, and Ravinder Dhawan for the original concept, acquisition of funding and expert advice.

\section{Appendix A. Supplementary data}

Supplementary material related to this article can be found, in the online version, at doi:https://doi.org/10.1016/j.jcpo.2021.100279.

\section{References}

[1] Italy used 5 indications in the adaptation: melanoma, 1L NSCLC, head and neck, bladder cancer, and renal cell carcinoma. This was due to the differences in the marketing authorization (EMA) and reimbursement approval (AIFA) timelines.

[2] The HIP model was developed by Adelphi Values under the sponsorship and methodological supervision of the Center for Observational and Real-world Evidence at Merck Sharp \& Dohme Corp., a subsidiary of Merck \& Co., Inc., Kenilworth, NJ, USA.

[3] Includes Pembrolizumab, Durvalumab, Atezolizumab, Nivolumab, and Avelumab.

[4] T. Hofmarcher, G. Brådvik, C. Svedman, P. Lindgren, B. Jönsson, N. Wilking, Comparator Report on Cancer in Europe 2019 - Disease Burden, Costs and Access to Medicines, IHE Report 2019, IHE, Lund, Sweden, 2019.

[5] M. Aitken, et al., Global oncology trends 2017. Advances, Complexity and Cost, Quintiles IMS Inst., 2017, pp. 1-40, no. June.

[6] ESMO, One in Two Patients With Metastatic Melanoma Alive After Five Years With Combination Immunotherapy (ESMO 2019 Press Release), 28 September 2019 2019.

[7] Business Wire, Outlook on the Global Oncology/Cancer Drugs Market to 2025, 2019. Accessed 29/10, 2019, https://www.businesswire.com/news/home/2 0191022005933/en/Outlook-Global-OncologyCancer-Drugs-Market-2025-Drug.

[8] IMS and Cowen and Co. data.

[9] S. Scala, K. Miner, J. Perreault, PD-1/PD-L1 Market Model Update - US Estimates, Cowen \& Company Equity Research "PD-1/PD-L1 Market Model Update", 2017, pp. 1-28. March 14.

[10] I. Hernandez, A. San-Juan-Rodriguez, C.B. Good, W.F. Gellad, Changes in list prices, net prices, and discounts for branded drugs in the US, 2007-2018, JAMA 323 (9) (2020) 854-862, https://doi.org/10.1001/jama.2020.1012.

[11] J. Weber, et al., Nivolumab versus chemotherapy in patients with advanced melanoma who progressed after anti CTLA 4 treatment (CheckMate 037): a randomised, controlled, open label, phase 3 trial, Lancet 16 (4) (2015) 375-384.

[12] J. Schachter, et al., Pembrolizumab versus ipilimumab for advanced melanoma: final overall survival results of a multicentre, randomised, open label phase 3 study (KEYNOTE 006), Lancet 390 (10105) (2017) 1853-1862.

[13] L. Paz Ares, et al., Pembrolizumab plus chemotherapy for squamous non-small cell lung Cancer, N. Engl. J. Med. (2018).

[14] L. Gandhi, et al., Pembrolizumab plus chemotherapy in metastatic non-small cell lung cancer, N. Engl. J. Med. (2018).

[15] M. Reck, et al., Pembrolizumab versus chemotherapy for pd 11 positive non-small cell lung cancer, N. Engl. J. Med. (375) (2016) 1823-1833.

[16] J. Brahmer, et al., Nivolumab versus docetaxel in advanced squamous cell nonsmall cell lung cancer, N. Engl. J. Med. (373) (2015) 123-135.

[17] J. Zhang, et al., Cisplatin and gemcitabine as the first line therapy in metastatic triple negative breast cancer, Int. J. Cancer (2015) 204-211.

[18] B. Burtness, et al., KEYNOTE 048: phase III study of first line pembrolizumab (P) for recurrent/metastatic head and neck squamous cell carcinoma (R/M HNSCC), Ann. Oncol. 29 (8) (2018).
[19] R. Ferris, et al., Nivolumab for recurrent squamous cell carcinoma of the head and neck, N. Engl. J. Med. (2016) 1856-1867.

[20] J. Bellmunt, et al., Pembrolizumab as second line therapy for advanced urothelial carcinoma, N. Engl. J. Med. (2017) 1015-1026.

[21] R. Motzer, et al., Nivolumab versus everolimus in advanced renal cell carcinoma, N. Engl. J. Med. (2015) 1803-1813.

[22] Due to the availability of more recent data, as well as the increase in physicians' experience in using anti-PD-1/PD-L1 agents, in their 2019 model updates, countries preferred to select the default trials based on the most commonly used treatment within a specified indication.

[23] Due to the objectives of the HIP - i.e., that overall class impact accuracy is more desirable than the high precision estimation of key parameters such as timedependent hazard rates via piecewise curve fitting, an exponential distribution was selected for the SOC curves as the simplest parametric model, as it incorporates a hazard function that is constant over time. The treatment effect is measured as a hazard ratio. After receiving expert validation of the approach taken, an exponential distribution was deemed the most appropriate method for SOC survival curve extrapolation. The accuracy improvement obtained from using more advanced extrapolation methods would be offset by underlying assumptions which would still be present, irrespective of the methods used for extrapolation.

[24] B. Woods, E. Sideris, S. Palmer, N. Latimer, M. Soares, NICE DSU TECHNICAL SUPPORT DOCUMENT 19: Partitioned Survival Analysis for Decision Modelling in Health Care: A Critical Review, 2 June, 2017.

[25] M. Drummond, G. Torrance, B. O'Brien, G. Stoddart, Methods for the Economic Evaluation of Health Care Programmes, Oxford University Press, USA, 2005.

[26] Peter J. Neumann, Gillian D. Sanders, Louise B. Russell, Joanna E. Siegel, Theodore G. Ganiats, (Eds.), Cost-Effectiveness in Health and Medicine, 2016, November 536 Pages.

[27] S.D. Sullivan, J.A. Mauskopf, F. Augustovski, et al., Budget impact analysisprinciples of good practice: report of the ISPOR 2012 budget impact analysis good practice II task force, Value Health 17 (1) (2014) 5-14.

[28] HIP country teams were comprised of country and headquarters MSD teams, country experts and consultants.

[29] Special session, J. Eur. Acad. Dermatol. Venereol. 31 (2017), 31-31.

[30] B.C. Registry, Cancer Incidence Projections in Belgium 2015-2025, 2017. Accessed 1st June, 2018, http://www.kankerregister.org/media/docs/publications/I ncidenceProj2015-2025_finaal_171120.pdf.

[31] Belgian Cancer Registry, Source, WHO, Globocan, 2020. https://gco.iarc.fr/today/ data/factsheets/populations/56-belgium-fact-sheets.pdf.

[32] Cancer in Slovenia, Cancer Registry of Republic of Slovenia, 2018, Institute of Oncology Ljubljana, Epidemiology and Cancer Registry, Ljubljana, 2015.

[33] T. Albreht, et al., Health system review. Health systems in transition, Slovenia 18 (3) (2016) 1-207.

[34] Active Ageing Strategy, Institute of Macroeconomic Analysis and Development of the Republic of Slovenia, Ljubljana, 2018.

[35] J. Ferlay, I. Soerjomataram, M. Ervik, R. Dikshit, S. Eser, C. Mathers, M. Rebelo, D. M. Parkin, D. Forman, F. Bray, GLOBOCAN 2012 v1.1, Cancer Incidence and Mortality Worldwide: IARC CancerBase No. 11 [Internet], International Agency for Research on Cancer, Lyon, France, 2014. Available from: http://globocan.iarc.fr, accessed on 18/09/2017.

[36] AIRTUM, I Numeri Del Cancro In Italia, 2019.

[37] Thomas Hofmarcher, Peter Lindgren, Nils Wilking, Bengt Jonsson, The Cost of Cancer in Europe 2018, Volume 129, 2020, pp. 41-49, https://doi.org/10.1016/j. ejca.2020.01.011. April.

[38] H.Y. Tu, Q. Zhang, Y.L. Wu, Optimal pembrolizumab dosing for non-small cell lung cancer: further studies still needed, J. Thorac. Dis. 9 (12) (2017) 4821-4824, https://doi.org/10.21037/jtd.2017.10.152.

[39] Martin Reck, Delvys Rodríguez-Abreu, Andrew G. Robinson, Rina Hui, Tibor Csőszi, Andrea Fülöp, Maya Gottfried, Nir Peled, Ali Tafreshi, Sinead Cuffe, Mary O'Brien, Suman Rao, Katsuyuki Hotta, Kristel Vandormael, Antonio Riccio, Jing Yang, M. Catherine Pietanza, R. Julie, Brahmer updated analysis of KEYNOTE024: pembrolizumab versus platinum-based chemotherapy for advanced non-small-Cell lung Cancer With PD-L1 tumor proportion score of $50 \%$ or greater, J. Clin. Oncol. 37:7 (March 01) (2019) 537-546, https://doi.org/10.1200/ JCO.18.00149. 